\title{
Fulvic acids separated from Suwannee River behavior in the aqueous- xylene system: influence of ionic strength and interaction with proteins
}

Chernysheva M.G., Badun G.A.

Lomonosov Moscow State University, Moscow, Russia, chernysheva@radio.chem.msu.ru

doi: 10.36291/HIT.2019.chernysheva.088

The behavior of compounds in the aqueous can be considered as a model of the interaction of the compounds with cellular membrane. The result of the interaction strongly depends on the conditions including $\mathrm{pH}$, salts concentration, presence of other compounds that can form composites and etc.

In present work we studied the behavior of fulvic acids separated from Suwannee River (SRFA, IHSS standard) in the aqueous-xylene system. We used tritium labeled SRFA to determine its concentration in the bulk of organic phase and at the liquid-liquid interface by means of scintillation phase method [1]. Two important conditions that can significantly affect humic substances were considered. They are ionic strength of the aqueous phase and the presence of proteins that can be encapsulated by humic materials.

The experiment was carried out in $0.028 \mathrm{M}$ phosphate buffer $(\mathrm{pH} \mathrm{6.8)}$ as well as in phosphate buffered saline $(0.16 \mathrm{M}, \mathrm{pH} 7.3)$ to analyze the influence of ionic strength on SRFA behavior. It was found that the increase in the ionic strength doesn't change the distribution ratio, while results in the increase of the adsorption as much as one order of magnitude.

In the studying the interference of SRFA and globular proteins during the adsorption at the liquid-liquid interface and distribution in the aqueous-xylene system hen egg white lysozyme and human serum albumin were used as model proteins. In these experiments' tritium label was contained either in protein or in SRFA.

It was found that both proteins reduce adsorption of SRFA, while adsorption of albumin in presence of SRFA was close to the adsorption of free protein, and it depended on the SRFA concentration in the case of lysozyme: at low SRFA concentrations it was lower than for free protein and exceeds this value for high SRFA concentration. Moreover, when SRFA was mixed with lysozyme the formation of insoluble complexes was observed as it was shown previously for coal humic acids [2]. Using tritium labeled materials we have determined the composition of the complex for different concentrations of SRFA.

The details of SRFA interaction with lysozyme and albumin will be discussed in the presentation.

Acknowledgements. This work was supported by Russian Foundation for Basic Research (grant \# 18-33-20147).

\section{References}

1. Chernysheva M.G. et al. // Chemosphere. 2020. 238: 124646. doi:10.1016/j.chemosphere.2019.124646.

2. Chernysheva M.G., Badun G.A. // In: Funct. Nat. Org. Matter Chang. Environ., Springer Netherlands, Dordrecht, 2013:280-291. doi:10.1007/978-94-007-5634-2_12. 